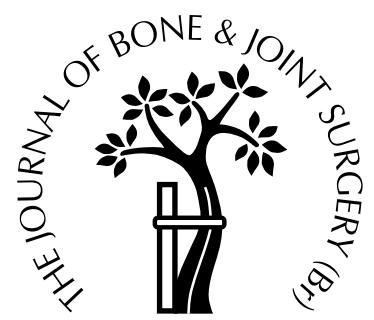

\title{
Patterns of weight distribution under the metatarsal heads
}

\author{
E. J. Luger, M. Nissan, A. Karpf, E. L. Steinberg, S. Dekel \\ From the Tel-Aviv Sourasky Medical Centre, Tel-Aviv, Israel
}

T The longitudinal arch between the heel and the forefoot and the transverse arch between the first and fifth metatarsal heads, absorb shock, energy and force. A device to measure plantar pressure was used in 66 normal healthy subjects and in 294 patients with various types of foot disorder. Only $22(3 \%)$ of a total of 720 feet, had a dynamic metatarsal arch during the stance phase of walking, and all had known abnormality.

Our findings show that there is no distal transverse metatarsal arch during the stance phase. This is important for the classification and description of disorders of the foot.

J Bone Joint Surg [Br] 1999;81-B:199-202.

Received 4 August 1998; Accepted after revision 30 September 1998

The function of the arches of the human foot is to absorb shock and energy and to transmit loading. ${ }^{1}$

There are three arches; a lateral system which involves the calcaneus, the cuboid and two lateral rays; a medial involving the calcaneus, talus, navicular, cuneiforms and the three medial rays; and a transverse formed by the bases of the metatarsals, the cuneiforms and the cuboid. ${ }^{2}$ The existence of another transverse arch at the level of the metatarsal heads (MTHs) is debatable. While some authors $^{1,3-6}$ have described such a structure, others ${ }^{7-9}$ deny its existence during the stance phase. No quantitative research is cited in any of these studies.

In recent years improved technology has allowed the direct measurement of plantar force and pressure distribution both dynamically and statically during barefoot-walking. ${ }^{10,11}$ We have used the Emed SF system (Novel GmbH,

E. J. Luger, MD

M. Nissan, $\mathrm{PhD}$

A. Karpf, DPM

E. L. Steinberg, MD

S. Dekel, MD

Department of Orthopaedics B, Tel-Aviv Sourasky Medical Centre, 6

Weizman Street, Tel-Aviv 64239, Israel.

Correspondence should be sent to Dr M. Nissan.

(C)1999 British Editorial Society of Bone and Joint Surgery

0301-620X/99/29353\$2.00

VOL. 81-B, No. 2, MARCH 1999
Munich, Germany) to investigate whether a distal dynamic transverse arch is present during the stance phase.

\section{Patients and Methods}

We tested 360 patients (720 feet). There were 161 women and 199 men, with a mean age of 51 years (SD 18.0, range 18 to 83 ) and a mean weight of $75 \pm 14 \mathrm{~kg}$. They had a variety of symptoms and abnormalities as described in Table I, but 41 women and 25 men were asymptomatic.

On all patients the distribution of plantar pressure under the bare feet was measured statically and dynamically by the Emed SF2 system. This is a capacitive pressure platform with 2016 sensors in an area of $445 \times 225 \mathrm{~mm}$ (2 sensors $/ \mathrm{cm}^{2}$ ) sampling at $71 \mathrm{~Hz}$. The platform is mounted flush in a wooden walkway, and covered by a thin layer of leather to camouflage and protect the plate. ${ }^{11-13}$ The "firststep' method $^{10}$ was used and the test was repeated three times on each foot for each patient. The patients were instructed to walk at their normal pace in a straight line and aimed to strike the Emed SF platform with one foot at a time. The data were analysed using the Novel-Win software (Novel GmbH, Munich, Germany). The maximum pressures of all sensors are shown on a colour-coded map of the feet (Fig. 1).

The existence of a transverse arch at the MTH would require the pressure at the mid-forefoot to be lower than under the first and fifth MTHs. To analyse the pressure distribution, the sole was divided into eight major areas, by

Table I. The number and gender of patients according to disorder

\begin{tabular}{lccr}
\hline & \multicolumn{3}{c}{ Number of patients } \\
\cline { 2 - 4 } Disorder & Female & Male & All \\
\hline Fracture & 12 & 17 & 29 \\
Cavus foot & 3 & 3 & 6 \\
Diabetes mellitus & 24 & 23 & 47 \\
Neuropathy & 21 & 40 & 61 \\
Hallux valgus & 12 & - & 12 \\
Pain* & 18 & 29 & 47 \\
Others $\dagger$ & 30 & 62 & 92 \\
Asymptomatic & 41 & 25 & 66 \\
\hline * metatarsalgia, joint pain, calcaneal & spur syndrome and \\
others & \multicolumn{4}{l}{} \\
$\dagger$ Achillis tendinitis, compartment & syndrome, sesamoi- \\
ditis, peripheral vascular disease, etc
\end{tabular}




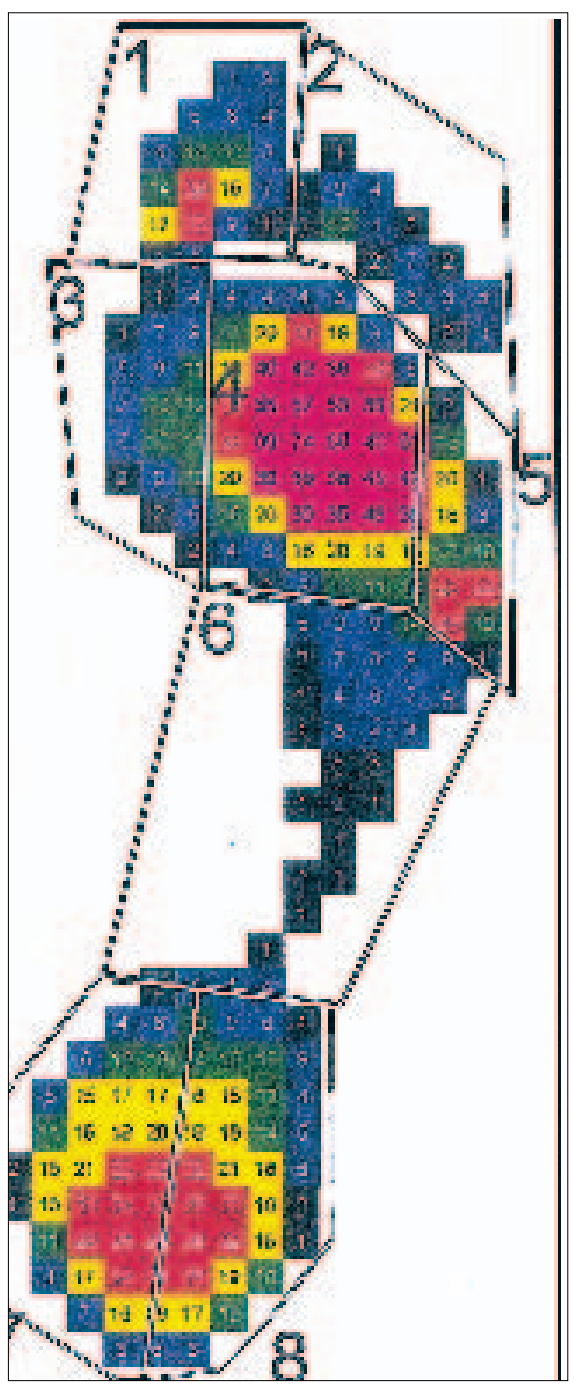

Fig. 1

The foot-pressure map and the eight 'masks' or zones used in the analysis (see text). creating 'masks' (Fig. 1) as follows: 1, under the big toe; 2, under the lesser toes (II to V); 3, under the first MTH; 4, under the second, third and fourth MTHs; 5, under the fifth MTH; 6, under the midfoot; 7, the medial aspect of the heel; and 8, the lateral aspect of the heel.

Figure 2 shows the maximum forces, normalised to body-weight, which were analysed in zones 3, 4 and 5 for the first, second to fourth, and fifth MTHs, respectively. In each patient both feet were measured independently. The results were analysed statistically. A paired $t$-test was used to compare the pressures at the MTHs according to gender and side. We used the non-parametric sign test to measure the number of metatarsal arches studied, the chi-squared method with Yates' correction to analyse the effect of gender on the metatarsal arch and the chi-squared method to determine the effect of symptoms.

\section{$\underline{\text { Results }}$}

We used the colour-coded map of the 720 feet to calculate the maximum pressures under the MTHs (Table II). There was no significant difference between men and women or between right and left feet ( $\mathrm{p}>0.999$ paired $t$-test).

In general, the second to fourth MTHs carried significantly higher forces $(p<0.01)$ than the first head, and significantly higher pressures than the fifth $(p<0.001)$ (Table II).

Of the 720 feet tested, we found a transverse arch in 22 (3\%) with pressures at the first and fifth MTHs higher than under the second to fourth MTHs (Table III). These included three of 12 cavus feet, two of 24 with hallux valgus, six of 122 with neuropathy, four of 94 painful feet, three of 94 in patients with diabetes mellitus and four other feet. The remainder had no sign of a transverse arch.

A significant sex-predominance was found (chi-squared with Yates' correction, $\mathrm{p}<0.05)$. The transverse arches were found mainly in men, despite a similar or even higher

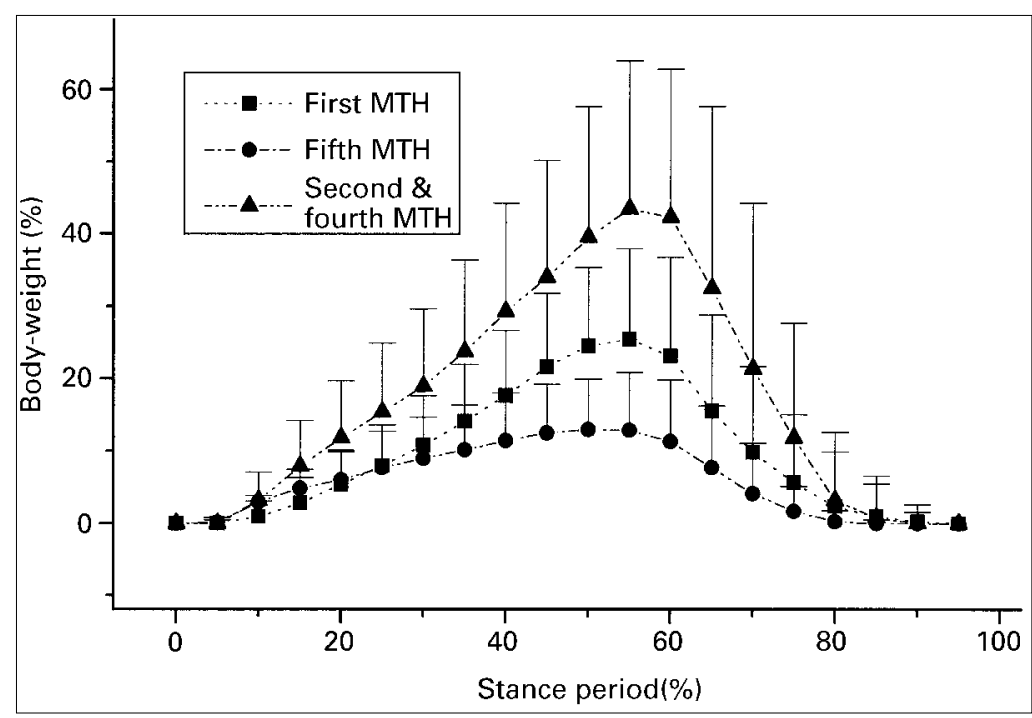

Fig. 2

Force at the MTH of asymptomatic volunteers during the stance phase. 
Table II. The mean ( $\pm \mathrm{SD})$ maximal pressures $\left(\mathrm{N} / \mathrm{cm}^{2}\right)$ under the first, second to fourth and fifth MTHs as determined using the Emed SF2 system in patients with and without a transverse arch

\begin{tabular}{|c|c|c|c|c|c|c|c|c|}
\hline & \multicolumn{4}{|c|}{ Right foot } & \multicolumn{4}{|l|}{ Left foot } \\
\hline & \multirow[b]{2}{*}{$\begin{array}{l}\text { Total } \\
\text { number }\end{array}$} & \multicolumn{3}{|l|}{ МTH } & \multirow[b]{2}{*}{$\begin{array}{l}\text { Total } \\
\text { number }\end{array}$} & \multicolumn{3}{|l|}{ MTH } \\
\hline & & First & $\begin{array}{l}\text { Second } \\
\text { to fourth }\end{array}$ & Fifth & & First & $\begin{array}{l}\text { Second } \\
\text { to fourth }\end{array}$ & Fifth \\
\hline \multicolumn{9}{|l|}{ Female } \\
\hline No arch & 158 & $24 \pm 13$ & $40 \pm 17$ & $18 \pm 10$ & 159 & $22 \pm 11$ & $41 \pm 17$ & $17 \pm 9$ \\
\hline With & 3 & $89 \pm 44$ & $26 \pm 4$ & $48 \pm 11$ & 2 & $46 \pm 2$ & $22 \pm 5$ & $39 \pm 11$ \\
\hline \multicolumn{9}{|l|}{ Male } \\
\hline No arch & 192 & $25 \pm 11$ & $42 \pm 13$ & $21 \pm 8$ & 189 & $24 \pm 10$ & $41 \pm 13$ & $21 \pm 8$ \\
\hline With & 7 & $60 \pm 20$ & $38 \pm 30$ & $64 \pm 35$ & 10 & $50 \pm 18$ & $22 \pm 13$ & $44 \pm 18$ \\
\hline Total & 360 & $25 \pm 14$ & $41 \pm 19$ & $19 \pm 10$ & 360 & $23 \pm 13$ & $41 \pm 19$ & $19 \pm 10$ \\
\hline
\end{tabular}

number of women with the same abnormality. A clear connection between the pathology and the number of metatarsal arches was found by the chi-squared method $(\mathrm{p}<0.01)$.

The time sequence of the forces on the MTH are shown in Figure 2. Since all forces are measured using transducers of the same surface area, the maximum forces represent the maximum pressures. The middle forefoot (zone 4) carried the main load during the stance phase of walking. Very similar results were found in the normal group, the patients with diabetes mellitus and the neuropathic groups. The standard error for the occurrence of a metatarsal arch was 0.0064 . The $95 \% \mathrm{CI}$ for the proportion of subjects and patients with a metatarsal arch in the population is thus between $1.8 \%$ and $4.3 \%$.

\section{Discussion}

The concept of a transverse arch at the level of the MTH was a common belief in the past. It was accepted as one of the major structures in the mechanism of energy absorption. ${ }^{1}$ It is still described in textbooks, ${ }^{4,5}$ and was in Gray's anatomy as recently as 1995 (38th edition). ${ }^{2}$ In recent years, with the introduction of various pressure platforms, the existence of a metatarsal arch has been questioned. Becker et $\mathrm{al}^{7}$ and Klenerman ${ }^{8}$ were among the first to refute its existence during the stance phase. The American Association of Orthopaedic Surgeons summed up the current belief in the USA as: "A transverse arch...is suggested to exist at the MTH when no weight is being borne; it does not exist during weight-bearing." 9 None of the authors supported their results with objective and quantitative data. We believe that our findings, the first quantitative study, will help to clarify the situation.

Our series involved patients and volunteers seen during the last two years. As a result we have a non-homogeneous population of both sexes with a variety of symptoms and disorders (Table I).

The variability in absolute maximum pressures was large, with significant standard deviations to over $60 \%$ of the average in our population (Table II). The variability, in absolute values, was affected by the weight, speed, foot pathology and other factors, but does not affect our find-
Table III. The number of feet with a transverse arch according to gender and disorder

\begin{tabular}{|c|c|c|c|c|}
\hline \multirow[b]{2}{*}{ Disorder } & \multicolumn{4}{|c|}{ Number of feet } \\
\hline & Female & Male & All & $(\%)$ \\
\hline Cavus foot & - & 3 & 3 & 25 \\
\hline Diabetes mellitus & & 3 & 3 & 3 \\
\hline Neuropathy & 1 & 5 & 6 & 5 \\
\hline Hallux valgus & 2 & - & 2 & 8 \\
\hline Pain* & - & 4 & 4 & 4 \\
\hline Others $†$ & 2 & 2 & 4 & 7 \\
\hline Total & 5 & 17 & 22 & 3 \\
\hline
\end{tabular}

* metatarsalgia, joint, pain, calcaneal spur syndrome and others

$\dagger$ Achillis tendonitis, compartment syndrome, sesamoiditis, peripheral vascular disease and fractures

ings. In all patients and in all feet (except for 22 feet, Table II), the pressures at the mid-forefoot beneath the second to fourth MTH was higher than the mean pressures of the medial and lateral aspects of the forefoot, namely the first and fifth MTH, respectively. The highest forces were found in the mid-forefoot in most patients. A paired $t$-test indicated that the pressure and force at the mid-forefoot is the highest, irrespective of gender or foot side. A significant gender difference was found, showing that males have increased evidence of an arch pattern. This finding has not been reported before and we do not have an explanation for it.

A transverse arch during the stance phase was found in 22 feet (3\% of the population). All cavus feet were expected to have a transverse arch, but this was found in only $50 \%$ of the men and in none of the women. Even patients with hallux valgus, with very high force and pressure under the first MTH, had a transverse arch in only $8 \%$ of feet; they had a significantly smaller force and pressure on their fifth MTH compared with the mid-forefoot area. A much lower incidence was found with other disorders (Table III). None of the asymptomatic volunteers had a transverse arch. A clear connection was found between abnormality in the foot and the incidence of a metatarsal arch. Since using the Emed system presents a maximum pressure picture for the whole stance phase, it does not exclude the possibility of a transverse arch at some point when the loading is not maximal. With the software we were able to analyse the change in pressure over time in the forefoot. The results for 
the asymptomatic subjects (Fig. 2) did not differ from those for the diabetic without neuropathy and neuropathic groups of patients. The force and pressure are highest in the midforefoot during the whole stance phase which includes periods with almost no weight-bearing.

The detailed analysis indicates that while there is always a longitudinal arch except in pathological cases, the dynamic transverse arch is found only in cases of cavus, hallux valgus or other deformities. A transverse arch indicates a possible pathological deformity.

No benefits in any form have been received or will be received from a commercial party related directly or indirectly to the subject of this article.

\section{References}

1. Kapandji LA. The physiology of the joints. Edinburgh \& London: E \& S Livingstone, 1970.

2. Williams PL, et al. Gray's anatomy. 38th Edition, New York, etc: Churchill-Livingstone, 1995.

3. Crouch JE. Functional human anatomy. 2nd ed. Philadelphia: Lea \& Febiger, 1972.
4. Norkin CC, Levangie PK. Joint structure and function: a comprehensive analysis. Philadelphia, F. A. Davis Co., 1995.

5. Whittle MW. Gait analysis: an introduction. Oxford: ButterworthHeinemann, 1991.

6. Wingate P. The Pengin medical encyclopedia. 2nd ed. Penguin Books, 1978.

7. Becker RF, Wilson JW, Gehweiler JA. The anatomical basis of medical practice. Baltimore: Williams \& Wilkins Co., 1971.

8. Klenerman L. Functional anatomy. 2nd ed. In: Klenerman L, ed. The foot and its disorders. Oxford, etc: Blackwell Scientific Publications, 1982.

9. Simon SR, Alaranta H, An K-N, et al. Kinesiology. In: Simon SR, ed. Orthopaedic basic science. Am Acad Orth Surg 1994;519-601.

10. Cavanagh PR, Ulbrecht JS. Biomechanics of the diabetic foot: a quantitative approach to the assessment of neuropathy, deformity and plantar pressure. In: Jahss MH, ed. Disorders of the foot and ankle, chapter 66. Philadelphia: W. B. Saunders, 2nd ed. 1991:1864-907.

11. Harrison AJ, Folland JP. Investigation of gait protocols for plantar pressure measurement of non-pathological subjects using a dynamic pedobarograph. Gait and Posture 1997;6:50-5.

12. Graf PM. The Emed Systed of foot pressure analysis. Clin Podiatr Med Surg 1993;10:445-54.

13. Perry JE, Ulbrecht JS, Derr JA, Cavanagh PR. The use of running shoes to reduce plantar pressures in patients who have diabetes. J Bone Joint Surg [Am] 1995;77-A:1819-28. 